\title{
Predictors of lost to follow-up in a "test and treat" programme among adult women with high-risk sexual behavior in Kampala, Uganda
}

Onesmus Kamacooko ${ }^{1 *}$ (D) Y Yunia Mayanja', Daniel Bagiire ${ }^{1}$, Gertrude Namale ${ }^{1}$, Christian Holm Hansen ${ }^{1,2}$ and Janet Seeley ${ }^{1,2}$

\begin{abstract}
Background: Immediate uptake of antiretroviral therapy (ART) after an HIV-positive diagnosis (Test and Treat) is now being implemented in Uganda. Data are limited on lost to follow-up (LTFU) in high-risk cohorts that have initiated 'Test and Treat'. We describe LTFU in a cohort of women of high-risk sexual behaviour who initiated ART under "Test and Treat".

Methods: We performed a retrospective cohort study of participant records at the Good Health for Women Project (GHWP) clinic, a clinic in Kampala for women at high-risk of HIV-infection. We included HIV positive women $\geq 18$ years who initiated ART at GHWP between August 2014 and March 2018. We defined LTFU as not taking an ART refill for $\geq 3$ months from the last clinic appointment among those not registered as dead or transferred to another clinic. We used the Kaplan-Meier technique to estimate time to LTFU after ART initiation. Predictors of LTFU were assessed using a multivariable Cox proportional hazards model.

Results: The mean $( \pm$ SD) age of the 293 study participants was $30.3( \pm 6.5)$ years, with $274(94 \%)$ reporting paid sex while 38 (13\%) had never tested for HIV before enrolment into GHWP. LTFU within the first year of ART initiation was $16 \%$ and the incidence of LTFU was estimated at 12.7 per 100 person-years (95\%CI 9.90-16.3). In multivariable analysis, participants who reported sex work as their main job at ART initiation (Adjusted Hazards Ratio [aHR] $=1.95,95 \% \mathrm{Cl} 1.10$ 3.45), having baseline WHO clinical stage III or IV (aHR=2.75, 95\% Cl 1.30-5.79) were more likely to be LTFU.
\end{abstract}

Conclusion: LTFU in this cohort is high. Follow up strategies are required to support women on Test and Treat to remain on treatment, especially those who engage in sex work and those who initiate ART at a later stage of disease.

Keywords: Universal test and treat, Women at high-risk, Lost to follow-up, Loss to follow-up; sub-Saharan Africa

\section{Background}

It is estimated that by the end of 2018, 23.3 million people were receiving antiretroviral therapy (ART) globally and that between 2000 and 2018, HIV-related deaths fell by

\footnotetext{
* Correspondence: Onesmus.Kamacooko@mrcuganda.org

'MRC/UVRI \& LSHTM Uganda Research Unit, Plot 51-59 Nakiwogo Road, P. O Box 49, Entebbe, Uganda

Full list of author information is available at the end of the article
}

45\% with 13.6 million lives saved due to ART in the same period [1]. In sub-Saharan Africa (SSA) access to ART has improved from 10.3 million people in 2015 to 12.9 million people by the end of 2018 [2]. In Uganda, by the end of 2018, it was estimated that 1.4 million people were living with HIV of whom $73 \%$ were on ART and an estimated 23,000 Ugandans had died of HIV-related illnesses [1]. In Uganda, the general population HIV prevalence has

C C The Author(s). 2020 Open Access This article is licensed under a Creative Commons Attribution 4.0 International License, which permits use, sharing, adaptation, distribution and reproduction in any medium or format, as long as you give appropriate credit to the original author(s) and the source, provide a link to the Creative Commons licence, and indicate if changes were made. The images or other third party material in this article are included in the article's Creative Commons licence, unless indicated otherwise in a credit line to the material. If material is not included in the article's Creative Commons licence and your intended use is not permitted by statutory regulation or exceeds the permitted use, you will need to obtain permission directly from the copyright holder. To view a copy of this licence, visit http://creativecommons.org/licenses/by/4.0/ The Creative Commons Public Domain Dedication waiver (http://creativecommons.org/publicdomain/zero/1.0/) applies to the data made available in this article, unless otherwise stated in a credit line to the data. 
stabilised at 6\% [3] while the prevalence among key populations (such as female sex workers [FSW]) is estimated to be over $30 \%$ [4]. Studies have shown that ART is not only improving quality of life and decreasing morbidity in those receiving treatment but that the public health impact of scaling up ART may contribute significantly to prevention efforts $[5,6]$. Recent studies have shown that early ART initiation reduced transmission of HIV and that there is great potential of treatment for prevention [6-8]. Given that the risk of HIV infections is high for key populations [9], this scale-up in ART is particularly important to maximize the effectiveness of treatment as prevention in such populations [10]. The scale up among key populations may have an impact on the HIV epidemic, since it is estimated that in SSA they contribute between 7 and 30\% of new infections $[11,12]$.

The scale-up of treatment can only be effective if people living with HIV remain on treatment following diagnosis and ART initiation, but retention in care remains a challenge in both high and low income settings [13]. With the current efforts aimed at initiating all HIV-positive individuals on immediate ART, regardless of CD4 and WHO clinical stage, in an approach called "Test and Treat" [14], retention in care is key if the full potential is to be realised including achieving the 90-9090 targets especially the 3rd 90 which is the one mostly affected by retention [15].

Treatment has become more widely available, but few data have been published on rates of retention and predictors of loss to follow-up (LTFU) among people at highrisk of HIV-infection enrolled on immediate ART. Studies carried out in the general population have shown that LTFU ranged between 14 and 18\% for the people living with HIV initiated on ART with some studies indicating that $41 \%$ of the LTFU occurred within the first 6 months of ART initiation [16-18]. We build on this work with a cohort of HIV positive women who started ART in a "Test and Treat" facility in Kampala, Uganda during the period of August 2014 to March 2018. We estimated the rate of LTFU and associated factors/predictors.

\section{Methods}

\section{Study design}

We performed a retrospective cohort study among women at high-risk of HIV infection, on ART, using records between August 2014 and March 2018.

\section{Study population and setting}

This study was embedded within an existing cohort of women living with HIV, or at high risk of HIV infection, attending the Good Health for Women Project (GHWP) clinic in Kampala. The GHWP clinic was established in a peri-urban community in southern Kampala in 2008 under the then Medical Research Council/Uganda Virus
Research Institute (MRC/UVRI), Uganda Research Unit on AIDS to study the epidemiology of HIV and sexually transmitted infections (STIs) and to implement HIV/STI prevention among high-risk women. Women attending the clinic engage in risky sexual behaviours such as sex with men for money, goods or favours; recruitment of women from commercial-sex hotspots has been described elsewhere [4]. All women were screened for eligibility and gave written consent before being enrolled in GHWP. Eligible women are then enrolled in the GHWP clinic irrespective of HIV status. The clinic offers routine HIV counselling and testing, syndromic management of STIs, family planning, antenatal care, free condoms, risk reduction counselling, counselling for excessive alcohol use, TB screening and treatment, ART and co-trimoxazole /dapsone preventive therapy. Enrolled women attend quarterly visits for HIV prevention and treatment services.

In August 2014, the GHWP clinic started the "test and treat" in accordance with new ART guidelines [19], which mandated that all people living with HIV should be initiated on ART irrespective of CD4 T-cell count and $\mathrm{WHO}$ clinical staging, as long as they were willing and ready to start treatment.

\section{Eligibility criteria}

All HIV positive women who initiated immediate ART at the clinic were eligible for screening into this study. Participants were included in this study if they met the following eligibility criteria: HIV positive women $\geq 18$ years and initiated ART between August 2014 and March 2018.

\section{Definition of study variables High-risk}

Women were classified as being at high-risk of HIVinfection if they were earning their living by exchanging sex for money, goods or other favors in lodges, on the street and around entertainment places. Women were also classified as being at high risk if they were illicit drug users, alcohol dependent and employed in entertainment facilities (for instance as waitress, massage attendants or entertainers/singers) where they may exchange sex for money after working hours, in order to supplement their income.

\section{Study outcome}

The study outcome was Lost to Follow-Up (LTFU) which we defined as not collecting ART refill for 3 months or longer from the last clinic appointment and not classified as dead or transferred for care to another clinic [20]. Women who had died or transferred their care to another clinic were censored at the time of their last visit and were not considered LTFU. The time to LTFU was calculated in months as the time interval 
between the date of ART initiation to the date of drop out (from ART initiation to first 3-month drop out), as recorded in the clinic ART database. All participants were followed until March 2018 unless they were LTFU, or had transferred or died before then.

\section{Independent variables}

Baseline characteristics at ART start were considered for this analysis. The sociodemographic characteristics considered were: participant's age at ART initiation, marital status, highest level of education attained, current job, behavioural characteristics were; ever being involved in paid sex, alcohol consumption patterns were assessed by using the Alcohol Use Disorders Identification Test (AUDIT) questionnaire which is a standardised tool developed by WHO. It consists of 10 questions to assess alcohol use disorders in the past 12 months [21], and, Clinical characteristics included: baseline WHO clinical stage, baseline CD4 cell count (cells/ $\mu \mathrm{l})$, year of ART start and ever tested for HIV before enrolling at the clinic.

\section{ART start and follow-up procedures}

The GHWP clinic staff gave information sessions about the 'Test and Treat' guidelines to women and the benefits to their health and the wider community. Women were also taught and counselled on disclosure, drug reactions, the importance of treatment adherence, and then individually assessed for readiness to start ART using the Ministry of Health (MoH) ART readiness assessment form [19]. Using the MoH ART guidelines, the initial ART prescriptions were for 2 weeks, then 1 month followed by an evaluation to check for any ART side effects, and then three-monthly ART refills. Attending an ART refill visit entailed visiting the clinic, seeing a physician, and receiving counselling before getting drugs from the pharmacy. First-line ART regimens dispensed at the clinic combined two nucleoside reverse transcriptase inhibitors (Tenofovir or Zidovudine and Lamivudine or Emtricitabine) and one non-nucleoside reverse transcriptase inhibitor (Nevirapine or Efavirenz).

\section{Follow up strategies for ART participants}

The pharmacist generates the list of women expected to come for ART refill. On a weekly basis, the field team follows up the clients (makes reminder calls) i.e. phone calling and physical visits either at home or at their places of work (hotspots) reminding them of their pending appointments.

In situations where the client has no telephone contact or their phone is unavailable, the field worker contacts a peer educator to pass over the information to the respective client/s. In case, the client misses the appointment and there is no documented reason for missing (reasons like travelled to the village, or to the islands, abroad etc.), then the field worker retrieves the locator form for such client and try to look for her physically, sometimes with the help of the peer educator or an influential person at the hotspot e.g. the lodge manager. When found, the field worker encourages such client to come and finds out the reasons for missing the appointment. The process continues until the client is located and encouraged to attend or declared lost to follow up.

\section{Sources of data}

Data were collected as part of routine clinical care monitoring and for research purposes within the clinic. Data entered in the clinic database (MS Access, Microsoft, Seattle, CA, USA) captured sociodemographic, alcohol use and sexual behaviour, clinical and reproductive health characteristics. HIV monitoring data such as HIV test results and all ART data were entered in an OpenMRS version 1.6.3 database which was merged with the GHWP database. Data were collected during one-onone private sessions held in clinic rooms with trained GHWP clinic counsellors. The pharmacy team captured data on ART refill dates, duration on ART, last ART refill dates and prescriptions. HIV antibody test results were recorded on laboratory source documents by laboratory staff while CD4 results were generated as printouts and entered manually into the OpenMRS database.

\section{Statistical analysis}

The MS Access and OpenMRS databases were merged into one database, cleaned, and exported to STATA 15.0 (StataCorp, College Station, TX, USA) for analysis. The participants' characteristics were summarised in descriptive terms such as mean, median, standard deviations (SD) or percentage, as appropriate. We used the KaplanMeier technique to estimate time to LTFU after ART initiation and present the estimated LTFU rates per 100 person-years for the study variables. LTFU rate was assessed within the first year of follow-up. Cox proportional hazards regression was used to determine independent predictors of LTFU among participants and these were expressed as estimated hazard ratios (HRs) with their corresponding 95\% confidence intervals (CIs). In the bivariate proportional hazards analysis, variables which gave a Likelihood Ratio Test (LRT) $p$-value less than 0.25 were subsequently considered for the adjusted model. In adjusted modelling, variables whose p-value was less than 0.05 were considered independent predictors of LTFU. We tested the validity of the overall model assumption by running a global test of the proportionalhazards assumption after fitting the model. We considered age at ART initiation and prior HIV testing a priori confounders; these were included in the multivariable model regardless of their unadjusted $p$ values. 
We further compared those who started ART at GHWP and those who did not to see if there were significant differences between the two groups in terms of the selected socio-demographic and clinical characteristics.

\section{Sensitivity analyses}

We conducted sensitivity analyses to address the issue of missing data on selected covariates. Participants who had missing data on some covariates were imputed using multivariate imputation by chained equations approach [22]. A sample of missing values were created, conditional on the distribution of the remaining covariates in the adjusted model. We assumed that the data were missing at random and carried out 10 rounds of multiple imputations; the final data for analysis after imputation were combined using Rubin's rule [23]. We compared the results from the complete case analysis and those from the imputed model.

\section{Ethical considerations}

The Uganda National Council for Science and Technology (HS 364) and Uganda Virus Research InstituteResearch Ethics Committee approved the study. Written informed consent was obtained from all participants. Data were de-identified prior to analysis of the numerical identifiers that were used during the data collection.

\section{Results}

Between August 2014 and March 2018, 3062 participants were cumulatively registered with GHWP of whom 1062 were HIV-positive and eligible for test and treat. During the study period, 44 more women who were originally negative became HIV positive and became eligible giving
$1106(44+1062)$ women. Of the 1106, 321 HIV-positive participants fully enrolled on "Test and Treat" of whom 293 (91.3\%) who had complete records were included in the analysis. Details are shown in the screening profile (Fig. 1).

\section{Baseline characteristics of women in the "test and treat" programme}

A total of 293 participants were included in the statistical analysis. The mean $( \pm \mathrm{SD})$ age of study participants was $30.3( \pm 6.5)$ years. Two hundred and fifty-five (87.0\%) had been tested for HIV before enrolment in GHWP, 196(66.9\%) were widowed or separated, $52(17.7 \%)$ were never married; $191(65.2 \%)$ were at WHO clinical stage I; $75(25.6 \%)$ were at WHO clinical stage II. One hundred ninety-seven (67.2\%) participants reported sex work as their current job. Those who reported no sex work had other jobs including working in an entertainment facility, a hotel/guest house or food vending; $3.1 \%$ reported being unemployed. The median baseline CD4 (IQR) was 530 (348-757) cells/ $\mu$ l (Table 1).

Compared with those included in the analysis, those who did not initiate ART at GHWP were not significantly different in terms of highest level of education attained. Furthermore, those included in the analysis were older, a higher proportion were married, a lower proportion reported sex work as their main job and had fewer had a prior HIV test when compared to those who did not initiate ART at GHWP. These were significantly different (Table 1).

\section{Lost to follow-up and associated factors}

Of the 293 enrolled participants, 16\% were LTFU within the first year of ART initiation. The median follow-up

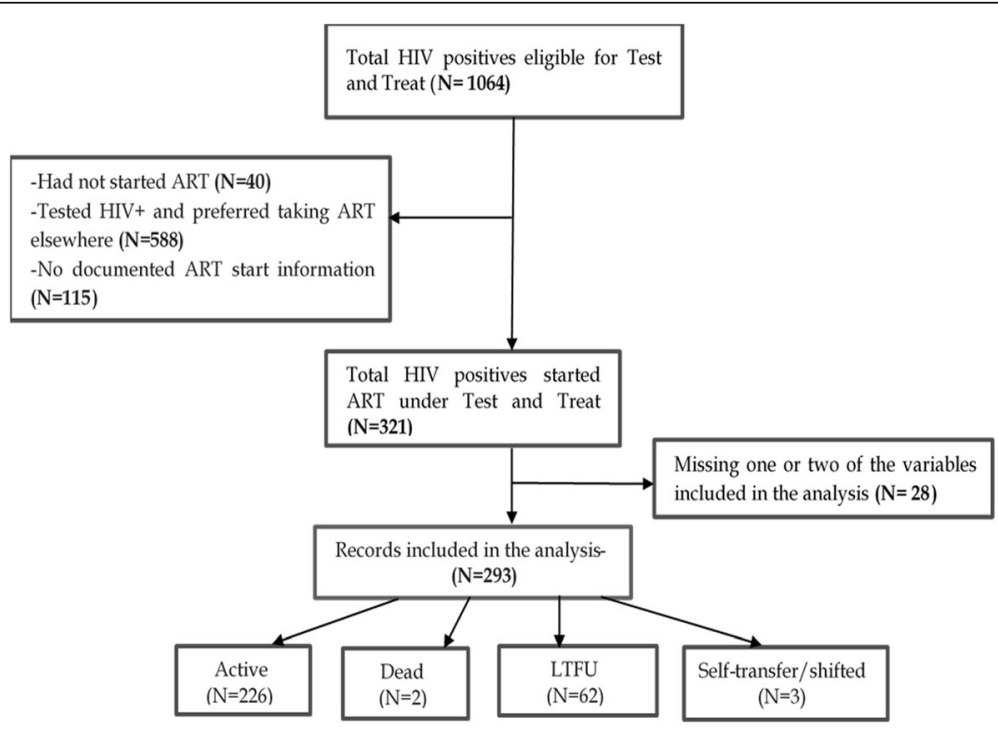

Fig. 1 Screening Profile of Study Participants 
Table 1 Baseline sociodemographic and clinical characteristics of the 293 study participants enrolled in the Test and Treat programme between August 2014 and March 2018 in Kampala Uganda

\begin{tabular}{|c|c|c|c|c|}
\hline Characteristics & Category & $\begin{array}{l}\text { Frequency } \\
\boldsymbol{N}=293 \text { n (col\%) }\end{array}$ & $\begin{array}{l}\text { Did not start ART at GHWP } \\
\boldsymbol{N}=588 \mathrm{n}(\mathrm{col} \%)\end{array}$ & $\begin{array}{l}\text { Chi-Square } \\
\boldsymbol{P} \text {-value }\end{array}$ \\
\hline Mean age (SD) & & $30.3(6.5)$ & $28.4(6.1)$ & $<0.001$ \\
\hline \multirow[t]{3}{*}{ Age at enrolment (year) } & $<25$ & $50(17.1)$ & $178(30)$ & $<0.001$ \\
\hline & $25-34$ & $175(59.7)$ & $303(52)$ & \\
\hline & $35+$ & $68(23.2)$ & $107(18)$ & \\
\hline \multirow[t]{3}{*}{ Marital Status } & Widowed/Separated & $196(66.9)$ & $425(72)$ & $<0.001$ \\
\hline & Married & $45(15.4)$ & $36(6)$ & \\
\hline & Never married & $52(17.7)$ & $127(22)$ & \\
\hline \multirow[t]{2}{*}{ Current job } & No sex work & $96(32.8)$ & $136(23)$ & 0.002 \\
\hline & Sex worker & $197(67.2)$ & $452(77)$ & \\
\hline \multirow[t]{3}{*}{ Highest formal education level attained } & No education & $37(12.6)$ & $60(10)$ & 0.553 \\
\hline & Attended Primary school & $177(60.4)$ & $363(62)$ & \\
\hline & Secondary school or higher & $79(27.0)$ & $165(28)$ & \\
\hline \multirow[t]{3}{*}{ Alcohol Consumption Patterns (AUDIT score) ${ }^{a}$} & Low risk & $113(38.6)$ & & \\
\hline & High risk & $119(40.6)$ & & \\
\hline & Dependent & $61(20.8)$ & & \\
\hline \multirow[t]{2}{*}{ Reported paid sex } & Yes & $274(93.5)$ & $575(98)$ & 0.001 \\
\hline & No & $19(6.5)$ & $13(2)$ & \\
\hline \multirow[t]{4}{*}{ Year of ART start ${ }^{a}$} & 2014 & $15(5.1)$ & & \\
\hline & 2015 & $75(25.6)$ & & \\
\hline & 2016 & $130(44.4)$ & & \\
\hline & 2017 & $73(24.9)$ & & \\
\hline \multirow[t]{3}{*}{ Baseline WHO stage ${ }^{a}$} & WHO Stage I & $191(65.2)$ & & \\
\hline & WHO Stage II & $75(25.6)$ & & \\
\hline & WHO Stage III \& IV & $27(9.2)$ & & \\
\hline Median CD4 count (IQR) & & $530(348,757)$ & & \\
\hline \multirow[t]{2}{*}{ Baseline CD4 count (cells/ul) Median (IQR) } & $0-350$ & $74(25.3)$ & & \\
\hline & Above 350 & $219(74.7)$ & & \\
\hline \multirow[t]{2}{*}{ Ever tested for HIV before enrolling at the clinic } & Yes & $255(87)$ & $560(95)$ & $<0.001$ \\
\hline & No & $38(13)$ & $28(5)$ & \\
\hline
\end{tabular}

SD Standard deviation, IQR Interquartile range; AUDIT Scores: 0-7 Low Risk, 8-19 High risk, $\geq 20$ Dependent; ${ }^{a}$ No available data for the comparison group

time was 1.77 years, with the longest follow-up being 3.6 years. At the end of the follow-up period, three records were censored due to known transfer out/shifted while two were due to death. We recorded a total of 488.15 person-years of follow up, and the estimated LTFU rate was 12.7 per 100 person-years (95\% CI 9.90-16.3). Figure 2 illustrates the survival curve for the time to LTFU after ART initiation during the follow-up period. Close to $90 \%$ of the participants were still in care after 12 months of follow-up.

In the unadjusted analysis, LTFU was more likely among those who reported sex work as their main job at ART initiation compared to those who reported no sex work (uHR 1.94; 95\% CI 1.03-3.43), and those who had baseline WHO clinical stage III or IV compared to those who had baseline WHO clinical stage I (uHR 2.97; 95\% CI 1.50-5.86).

In the adjusted model, participants who reported sex work as their current job at ART start were at a higher risk of LTFU (aHR 1.95; 95\%CI 1.10-3.45) while those who had baseline WHO clinical stage III or IV were at higher risk of LTFU (aHR 2.75; 95\%CI 1.30-5.79) compared to those who had baseline WHO clinical stage I. (Table 2). The global test results showed $p>$ 0.05 thus we do not have a violation of the proportional assumption. 


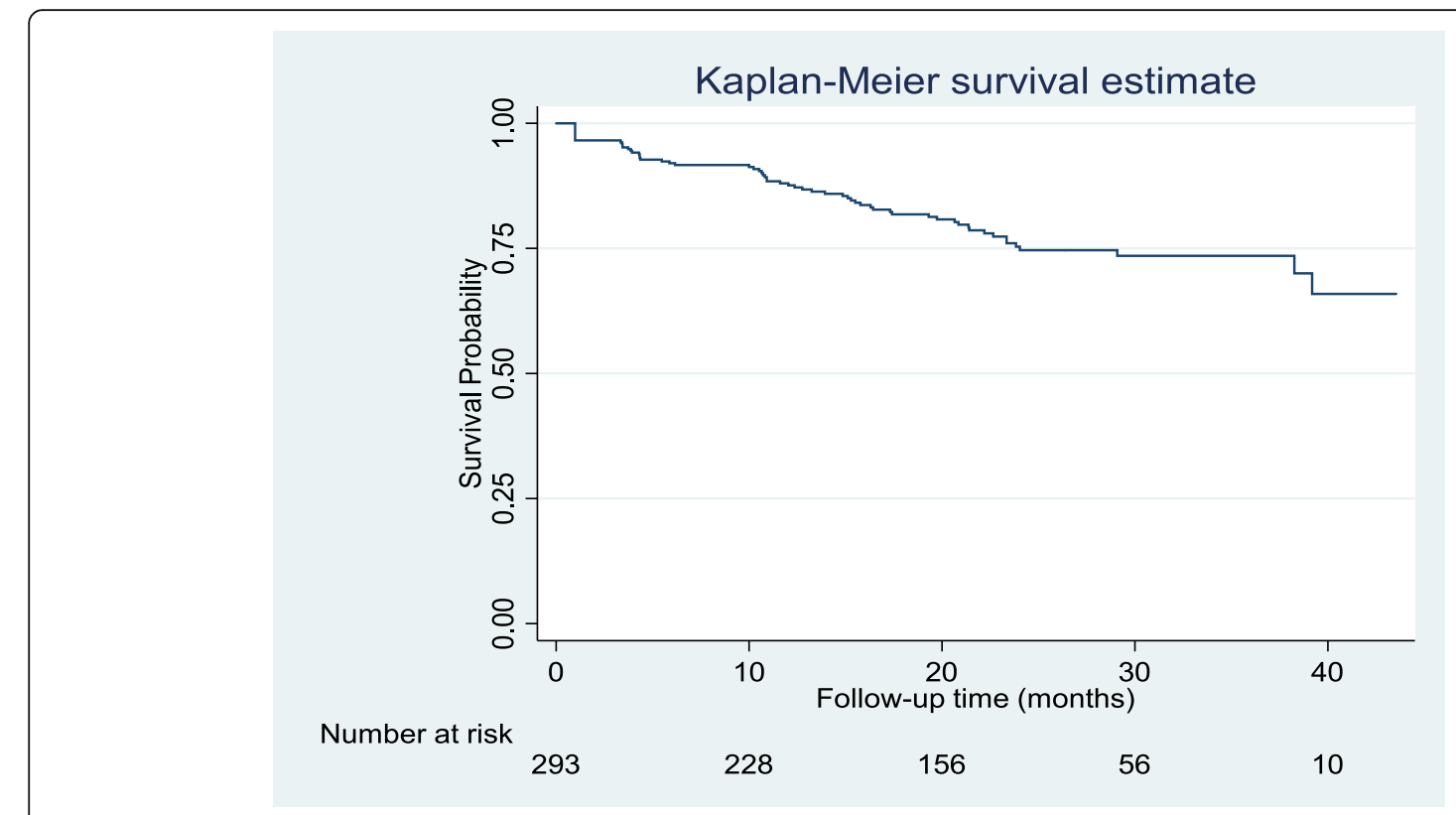

Fig. 2 Kaplan-Meier plot showing LTFU of participants during the follow-up period

\section{Sensitivity analysis results}

A sensitivity analysis by imputing data of participants who had missing data on some covariates $(n=28)$ was done and the results were similar to when they were excluded.

\section{Discussion}

In this study, we illustrate high rates of LTFU in a cohort of early adopter, test and treat recipients of Ugandan women at high risk of HIV-infection. Our study revealed that the overall LTFU rate was 12.7 per 100 person-years. The proportion of LTFU of $16 \%$ in the first year of ART initiation in this study is high compared to the overall results of the meta analysis of attrition among FSWs that was reported at 6\% [24]. In studies carried out among high-risk populations in coastal Kenya, high rates of LTFU were found among men who have sex with men (MSM) (14.5/100 PYAR) which is consistent with our study and lower rates among women (10.4/100 PYAR) [25]. Other studies carried out in the general population in subSaharan Africa and elsewhere showed lower LTFU rates ranging between 7.1-11.6 [18, 26, 27]. Some of the variations in the incidence rates might be explained by the differences in the populations studied especially with those in the general populations, as our study was carried out among a high-risk population. For the studies carried out in a similar population, the differences might be explained by the follow-up strategies that are used to reach to these participants [28].

Women who reported sex work as their current job at the time of ART initiation were more likely to be LTFU compared to those who reported other jobs. Studies carried out in sub-Saharan Africa, the Caribbean and elsewhere have found that FSWs are highly mobile and because of this, it is hard for them to access secure housing, supportive networks and regular income, this makes it hard for them to start and stay on ART [24, 29, 30]. In the qualitative studies carried out among FSWs seeking ART/general care services, major concerns were rude remarks from providers, delay of services and potential for breach of confidentiality [30, 31]. Although we did not assess this, we assume that might explain why some FSWs are likely to get lost after initiating prompt ART. Many FSWs have a lifestyle which poses barriers to stabilise on treatment such as high alcohol intake, fear of being seen taking drugs which might result into losing their clients [32, 33].

There is a need to establish strategies targeting sex workers to improve access to ART services conveniently for example giving them special attention and according them respect and continued assurance of confidentiality when they come for drug refills and appointments. In addition to the close monitoring and intensive follow-up at the GHWP clinic, there is a need to have a sex workersupportive environment through community engagements among FSWs so that universal access to HIV services and acceptable ART delivery strategies can be identified [34].

In our study, we found that women who had baseline clinical stage III or IV were more likely to get lost to follow-up compared to those with baseline clinical stage I. Our results are consistent with case-control studies that were carried out in Uganda, Ethiopia and in another study carried out in antiretroviral treatment (ART) clinics in Tanzania, Uganda and Zambia to assess predictors of attrition [35-37]. Though we did not trace participants in 
Table 2 Multivariable analysis of predictors of Lost to follow-up among study participants enrolled in the Test and Treat programme between August 2014 and March 2018 in Kampala Uganda

\begin{tabular}{|c|c|c|c|c|c|}
\hline \multirow{2}{*}{ Participant's Characteristics } & \multirow[b]{2}{*}{ Category } & \multicolumn{2}{|l|}{$\mathrm{N}=62$} & \multirow{2}{*}{$\begin{array}{l}\text { LRT } \\
\text { p-value aHR(95\%Cl) }\end{array}$} & \multirow{2}{*}{$\begin{array}{l}\text { Wald } \\
\text { P-value }\end{array}$} \\
\hline & & $\operatorname{LTR}(95 \% \mathrm{Cl})$ & $\mathrm{uHR}(95 \% \mathrm{Cl})$ & & \\
\hline \multirow[t]{4}{*}{ Age at enrolment(year) } & & & & 0.421 & 0.873 \\
\hline & $<25$ & 19.3(11.0-34.1) & & & \\
\hline & $25-34$ & $11.6(8.3-16.2)$ & $0.63(0.33-1.22)$ & $0.95(0.45-1.20)$ & \\
\hline & $35+$ & $12.0(7.24-19.9)$ & $0.66(0.31-1.41)$ & $1.12(0.48-2.61)$ & \\
\hline \multirow[t]{4}{*}{ Marital Status } & & & & 0.15 & 0.156 \\
\hline & Widowed/Separated & $8.96(3.36-23.9)$ & & & \\
\hline & Married & $11.5(8.50-15.7)$ & $1.39(0.49-3.91)$ & $1.65(0.58-4.68)$ & \\
\hline & Never married & $19.3(12.0-40.0)$ & $2.32(0.77-6.95)$ & $2.61(0.86-7.92)$ & \\
\hline \multirow[t]{3}{*}{ Current job } & & & & 0.017 & 0.023 \\
\hline & Other jobs & $8.1(5.02-13.0)$ & & & \\
\hline & Sex worker & $16.2(12.1-21.7)$ & $1.94(1.10-3.43)$ & $1.95(1.10-3.45)$ & \\
\hline \multirow[t]{4}{*}{ Highest formal education level attained } & & & & 0.452 & \\
\hline & No education & 15.3(7.9-29.4) & & & \\
\hline & Attended Primary school & $13.9(10.1-19.2)$ & $0.93(0.45-1.93)$ & & \\
\hline & Secondary school or higher & 9.6(5.8-15.9) & $0.66(0.29-1.51)$ & & \\
\hline \multirow[t]{4}{*}{ Alcohol Consumption Patterns(AUDIT score } & & & & 0.801 & \\
\hline & Low risk & $12.9(8.6-19.2)$ & & & \\
\hline & High risk & $13.5(9.2-19.6)$ & $1.06(0.61-1.83)$ & & \\
\hline & Dependent & $10.9(6.0-19.6)$ & $0.84(0.41-1.71)$ & & \\
\hline \multirow[t]{3}{*}{ Paid sex } & & & & 0.69 & \\
\hline & Yes & $12.9(10.0-16.7)$ & & & \\
\hline & No & $10.2(3.8-27.1)$ & $0.82(0.29-2.27)$ & & \\
\hline \multirow[t]{4}{*}{ Baseline WHO stage } & & & & 0.016 & 0.029 \\
\hline & WHO Stage I & $10.1(7.3-14.1)$ & & & \\
\hline & WHO Stage II & 14.8(9.1-24.2) & $1.39(0.77-2.51)$ & $1.32(0.73-2.41)$ & \\
\hline & WHO Stage III \& IV & $31.7(17.6-57.3)$ & $2.97(1.50-5.86)$ & $2.75(1.30-5.79)$ & \\
\hline \multirow[t]{3}{*}{ Baseline CD4 count (cells/ $/ \mu$ ) } & & & & 0.892 & \\
\hline & $0-350$ & $13.0(8.0-21.3)$ & & & \\
\hline & Above 350 & $12.6(9.4-16.8)$ & $0.96(0.54-1.70)$ & & \\
\hline \multicolumn{2}{|l|}{ Ever tested for HIV before enrolling at the clinic } & & & 0.079 & 0.138 \\
\hline & Yes & 13.9(10.8-18.1) & & & \\
\hline & No & $6.2(2.6-14.9)$ & $0.48(0.19-1.19)$ & $0.50(0.20-1.25)$ & \\
\hline
\end{tabular}

"significant at $P<0.05 ;$ HR Hazard Ratio, I Confidence Interval, LRT Likelihood Ratio Test, LTR Estimated LTFU rate per 100 person-years, uHR Unadjusted Hazard Ratio, aHR Adjusted Hazard Ratio, Wald Wald Chi-square $P$-value; global test chi-square value $=6.90$ and $p$-value $=0.548$

an advanced stage, studies done in SSA have shown that this group tends to die early [38]. However, our results contradict the findings of the study carried out in Ethiopia in a general population which found out that clinical WHO stage III was not associated with LTFU [39]. This difference might be due to the difference in study settings where this study in Ethiopia was carried out in governmental health institutions (3 health centres and 2 Hospitals) which provide ART service for the town and surrounding population while our study was carried out in a dedicated clinic that follows high risk women. Therefore, this group needs to be targeted and encouraged to always stay in care in order to achieve the 90-90-90 targets.

\section{Study limitations}

The main limitation is that we had 62 LTFU events from our study, we believe a bigger study might have detected further risk factors. We believe the fewer events might affect our generalizability.
Another limitation was missing data on some of the variables that were included in the analysis. Of the 321 that enrolled on "test and treat" at GHWP clinic, only $(91.3 \% ; 293 / 321)$ had all the data available for analysis on the selected variables. We however did the sensitivity analysis which showed no differences in the results with all the missing data imputed.

We used secondary data; some of the data that may influence the risk of LTFU such as social support were not available. We believe such explanations would inform future strategies of targeting groups of high-risk women on ART. Notwithstanding these constraints, we believe that our results will give an imperative understanding of the magnitude and the factors associated with LTFU among high-risk cohorts in the test and treat era.

\section{Recommendation for further research}

We recommend a qualitative research study among the high-risk cohorts by exploring the barriers and challenges 
of this group in regard to LTFU. This should focus on other behavioural characteristics.

\section{Conclusion}

Our findings report a high rate of lost to follow-up in this cohort. Follow up strategies are required to support women who initiate Test and Treat to, especially those who engage in sex work as their main job and those who initiate ART at a later stage of disease.

\begin{abstract}
Abbreviations
aHR: Adjusted Hazard ratio; ART: Anti-retroviral treatment; AUDIT: Alcohol Use Disorders Identification Test; CD4: Cluster of differentiation 4; Cl: Confidence Interval; FSWs: Female sex workers; GHWP: Good Health for Women Project; HIV: Human Immunodeficiency Virus; LRT: Likelihood Ratio Test; LTFU: Lost to Follow-up; MoH: Ministry of Health; MRC/UVRI and LSHTM: Medical Research Council/ Uganda Virus Research Institute and London School of Hygiene and Tropical Medicine; MSM: Men who have sex with men; PYAR: Person years at risk; SD: Standard deviation; SSA: Sub-Saharan Africa; STIs: Sexually Transmitted Infections; UHR: Unadjusted Hazard ratio; UNCST: Uganda National Council for Science and Technology; UVRI-REC: Uganda Virus Research Institute-Research Ethics Committee; WHO: World Health Organization
\end{abstract}

\section{Acknowledgements}

We acknowledge the study participants and all the MRC/UVRI \& LSHTM Uganda research unit staff who participated in data collection.

\section{Authors' contributions}

DB participated in data cleaning and OK did the analysis and write up of the results. OK drafted the original concept while YM and GN coordinated the study and oversaw the overall execution of the manuscript writing, $\mathrm{CHH}$ gave the guidance on the statistics and analysis, JS directed, sourced funding and oversaw the critical revisions of the manuscript. All authors contributed to and approved the final version of this manuscript.

\section{Funding}

There was no separate funding for this study.

\section{Availability of data and materials}

Data used for this paper will not be shared publically but if there is a need for this data, then data can be shared by following the data sharing policy of MRC/UVRI \& LSHTM Uganda research unit. This policy can be access through this link https://www.mrcuganda.org/publications/data-sharing-policy.

\section{Ethics approval and consent to participate}

The Uganda National Council for Science and Technology/ UNCST (HS 1584) and Uganda Virus Research Institute-Research Ethics Committee/ UVRI-REC (GC/127/14/04/454) approved the study. Written informed consent to take part in the study was obtained from all participants and confidentiality was kept by use of numerical identifiers.

\section{Consent for publication}

Not applicable.

\section{Competing interests}

The authors declare that they have no competing interests.

\section{Author details}

1MRC/UVRI \& LSHTM Uganda Research Unit, Plot 51-59 Nakiwogo Road, P. O Box 49, Entebbe, Uganda. 'London School of Hygiene and Tropical Medicine, Keppel Street, London WC1E 7HT, UK.
Received: 17 September 2019 Accepted: 2 March 2020

Published online: 18 March 2020

\section{References}

1. WHO: HIV/AIDS facts sheet. 2018

2. UNAIDS: Global AIDS update 2018.

3. Uganda AIDS Commission. HIV/AIDS Country Progress report; July 2016June 2017. Kampala: Uganda AIDS Commission; 2017.

4. Vandepitte J, Bukenya J, Weiss HA, Nakubulwa S, Francis SC, Hughes P, Hayes R, Grosskurth H. HIV and other sexually transmitted infections in a cohort of women involved in high-risk sexual behavior in Kampala, Uganda. Sex Transm Dis. 2011;38(4):316-23.

5. Delva W, Eaton JW, Meng F, Fraser C, White RG, Vickerman P, Boily MC, Hallett TB. HIV treatment as prevention: optimising the impact of expanded HIV treatment programmes. PLoS Med. 2012;9(7):e1001258.

6. Asiki G, Reniers G, Newton R, Baisley K, Nakiyingi-Miiro J, Slaymaker E, Kasamba I, Seeley J, Todd J, Kaleebu P, et al. Adult life expectancy trends in the era of antiretroviral treatment in rural Uganda (1991-2012). AIDS (London, England). 2016;30(3):487-93.

7. Cohen MS, Chen YQ, McCauley M, Gamble T, Hosseinipour MC, Kumarasamy N, Hakim JG, Kumwenda J, Grinsztejn B, Pilotto JH, et al. Prevention of HIV-1 infection with early antiretroviral therapy. N Engl J Med. 2011;365(6):493-505

8. Eaton JW, Johnson LF, Salomon JA, Barnighausen T, Bendavid E, Bershteyn A, Bloom DE, Cambiano V, Fraser C, Hontelez JA, et al. HIV treatment as prevention: systematic comparison of mathematical models of the potential impact of antiretroviral therapy on HIV incidence in South Africa. PLoS Med. 2012;9(7):e1001245.

9. Baral S, Beyrer C, Muessig K, Poteat T, Wirtz AL, Decker MR, Sherman SG, Kerrigan D. Burden of HIV among female sex workers in low-income and middle-income countries: a systematic review and meta-analysis. Lancet Infect Dis. 2012;12(7):538-49.

10. Montague BT, Vuylsteke $B$, Buve A. Sustainability of programs to reach high risk and marginalized populations living with HIV in resource limited settings: implications for HIV treatment and prevention. BMC Public Health. 2011;11:701

11. Djomand G, Quaye S, Sullivan PS. HIV epidemic among key populations in West Africa. Curr Opin HIV AIDS. 2014;9(5):506-13.

12. Gouws E, Cuchi P. Focusing the HIV response through estimating the major modes of HIV transmission: a multi-country analysis. Sex Transm Infect. 2012;88(Suppl 2):i76-85.

13. Wubshet M, Berhane Y, Worku A, Kebede Y, Diro E. High loss to followup and early mortality create substantial reduction in patient retention at antiretroviral treatment program in north-West Ethiopia. Isrn aids. 2012;2012 721720

14. WHO: Consolidated guidelines on the use of antiretroviral drugs for treating and preventing HIV infection Recommendations for a public health approach - Second edition. 2016.

15. UNAIDS: 90-90-90: an ambitious treatment target to help end the AIDS epidemic. 2014. Available at: https://www.unaids.org/en/resources/ documents/2017/90-90-90. Accessed 18 Dec 2019.

16. Geng EH, Odeny TA, Lyamuya R, Nakiwogga-Muwanga A, Diero L, Bwana M Braitstein P, Somi G, Kambugu A, Bukusi E, et al. Retention in care and patient-reported reasons for undocumented transfer or stopping care among HIV-infected patients on antiretroviral therapy in eastern Africa: application of a sampling-based approach. Clin Infect Dis. 2016;62(7):935-44.

17. Guy R, Wand H, McManus H, Vonthanak S, Woolley I, Honda M, Read T, Sirisanthana T, Zhou J, Carr A. Antiretroviral treatment interruption and loss to follow-up in two HIV cohorts in Australia and Asia: implications for 'test and treat' prevention strategy. AIDS Patient Care STDs. 2013;27(12):681-91.

18. Tadesse K, Haile F. Predictors of loss to follow up of patients enrolled on antiretroviral therapy: a retrospective cohort study. J AIDS Clin Res. 2014; 5(12):393.

19. $\mathrm{MoH}$ : Consolidated Guidelines for Prevention and Treatment of HIV in Uganda. 2016

20. Chi BH, Yiannoutsos CT, Westfall AO, Newman JE, Zhou J, Cesar C, Brinkhof MW, Mwango A, Balestre E, Carriquiry G, et al. Universal definition of loss to follow-up in HIV treatment programs: a statistical analysis of 111 facilities in Africa, Asia, and Latin America. PLoS Med. 2011;8(10):e1001111. 
21. World Health O. AUDIT : the Alcohol Use Disorders Identification Test : guidelines for use in primary health care / Thomas F. Babor ... [et al.]. 2nd ed. Geneva: World Health Organization; 2001.

22. Sterne JA, White IR, Carlin JB, Spratt M, Royston P, Kenward MG, Wood AM, Carpenter JR. Multiple imputation for missing data in epidemiological and clinical research: potential and pitfalls. BMJ (Clin Res ed). 2009;338:b2393.

23. Rubin D. Statistical analysis with missing data; 1987.

24. Mountain E, Mishra S, Vickerman P, Pickles M, Gilks C, Boily MC. Antiretroviral therapy uptake, attrition, adherence and outcomes among HIV-infected female sex workers: a systematic review and meta-analysis. PLoS One. 2014; 9(9):e105645.

25. Graham SM, Mugo P, Gichuru E, Thiong'o A, Macharia M, Okuku HS, van der Elst E, Price MA, Muraguri N, Sanders EJ. Adherence to antiretroviral therapy and clinical outcomes among young adults reporting high-risk sexual behavior, including men who have sex with men, in coastal Kenya. AIDS Behav. 2013;17(4):1255-65.

26. Assemie MA, Muchie KF. Incidence and predictors of loss to follow up among HIV-infected adults at Pawi General Hospital, northwest Ethiopia: competing risk regression model. BMC Res Notes. 2018;1 1(1):287.

27. Alvarez-Uria G, Naik PK, Pakam R, Midde M. Factors associated with attrition, mortality, and loss to follow up after antiretroviral therapy initiation: data from an HIV cohort study in India. Glob Health Action. 2013;6(1):21682.

28. McMahon JH, Elliott JH, Hong SY, Bertagnolio S, Jordan MR. Effects of physical tracing on estimates of loss to follow-up, mortality and retention in low and middle income country antiretroviral therapy programs: a systematic review. PLoS One. 2013;8(2):e56047.

29. Chersich MF, Luchters S, Ntaganira I, Gerbase A, Lo YR, Scorgie F, Steen R. Priority interventions to reduce HIV transmission in sex work settings in subSaharan Africa and delivery of these services. J Int AIDS Soc. 2013;16:17980.

30. Scorgie F, Nakato D, Harper E, Richter M, Maseko S, Nare P, Smit J, Chersich M. We are despised in the hospitals': sex workers' experiences of accessing health care in four African countries. Culture Health Sex. 2013;15(4):450-65.

31. Wanyenze RK, Musinguzi G, Kiguli J, Nuwaha F, Mujisha G, Musinguzi J, Arinaitwe J, JKB M. "When they know that you are a sex worker, you will be the last person to be treated": perceptions and experiences of female sex workers in accessing HIV services in Uganda. BMC Int Health Hum Rights. 2017;17(1):11.

32. Mbonye M, Rutakumwa $\mathrm{R}$, Weiss $\mathrm{H}$, Seeley J. Alcohol consumption and high risk sexual behaviour among female sex workers in Uganda. Afr J AIDS Res. 2014;13(2):145-51.

33. Chakrapani V, Newman PA, Shunmugam M, Kurian AK, Dubrow R. Barriers to free antiretroviral treatment access for female sex Workers in Chennai, India. AIDS Patient Care STDs. 2009;23(11):973-80.

34. Estill J, Kerr CC, Blaser N, Salazar-Vizcaya L, Tenthani L, Wilson DP, Keiser O. The Effect of Monitoring Viral Load and Tracing Patients Lost to Follow-up on the Course of the HIV Epidemic in Malawi: A Mathematical Model. Open Forum Infect Dis. 2018;5(5):ofy092

35. Nakiwogga-Muwanga A, Alamo-Talisuna S, Musaazi J, Kambugu A, Ssekawungu P, Katabira E, Colebunders R. Inadequate monitoring in advanced stages of disease with lack of supportive counseling increases attrition among patients on antiretroviral treatment at a large urban clinic in Uganda. J Int Assoc Providers AIDS Care. 2014;13(6):547-54.

36. Megerso A, Garoma S, Eticha T, Workineh T, Daba S, Tarekegn M, Habtamu Z. Predictors of loss to follow-up in antiretroviral treatment for adult patients in the Oromia region, Ethiopia. HIV AIDS (Auckl). 2016;8:83-92.

37. Koole O, Tsui S, Wabwire-Mangen F, Kwesigabo G, Menten J, Mulenga M, Auld A, Agolory S, Mukadi YD, Colebunders R, et al. Retention and risk factors for attrition among adults in antiretroviral treatment programmes in Tanzania, Uganda and Zambia. Trop Med Int Health : TM \& IH. 2014;19(12):1397-410.

38. Brinkhof MWG, Boulle A, Weigel R, Messou E, Mathers C, Orrell C, Dabis F, Pascoe M, Egger M, for the international epidemiological Databases to Evaluate A. Mortality of HIV-infected patients starting antiretroviral therapy in sub-Saharan Africa: comparison with HIV-unrelated mortality. PLoS Med. 2009;6(4):e1000066.

39. Seifu W, Ali W, Meresa B. Predictors of loss to follow up among adult clients attending antiretroviral treatment at Karamara general hospital, Jigjiga town, eastern Ethiopia, 2015: a retrospective cohort study. BMC Infect Dis. 2018; 18(1):280.

\section{Publisher's Note}

Springer Nature remains neutral with regard to jurisdictional claims in published maps and institutional affiliations.

\section{Ready to submit your research? Choose BMC and benefit from}

- fast, convenient online submission

- thorough peer review by experienced researchers in your field

- rapid publication on acceptance

- support for research data, including large and complex data types

- gold Open Access which fosters wider collaboration and increased citations

- maximum visibility for your research: over $100 \mathrm{M}$ website views per year

At BMC, research is always in progress.

Learn more biomedcentral.com/submissions 